\title{
Cost-benefits Analysis of K12 Education in the United States
}

\author{
Lili Shi ${ }^{1, a}$, Baolong $\mathrm{Yu}^{2}{ }^{2}$ b, Shurong $\mathrm{Yu}^{3,}$, Ziping $\mathrm{He}^{4, \mathrm{~d}}$ \\ 1. School of Economics, Huazhong University of Science and Technology, Wuhan, China \\ 2. School of Business, Qingdao University of Technology, Qingdao, China \\ 3. School of business, Ningbo University, Ningbo, China \\ 4. College of Tourism and Service Management, Nankai University, Tianjin, China \\ a 2027063357@qq.com, b baolong1715023566@163.com, cYushurong-fancyzi@outlook.com, \\ d1913728@mail.nankai.edu.cn
}

\begin{abstract}
By taking American Basic Education (K12) as a whole and using the data from NECS and the Georgetown University Center on education and the workforce, we made a Cost-benefitsanalysis. The analysis shows that the net benefits of k12 education is 38656 billion and the return is an amazing $458 \%$.
\end{abstract}

Keywords: k12 Education; Cost-benefits-analysis.

\section{Overview and Introduction}

As part of the national strategy, education is also an important way for personal development, which plays an extremely important role for both the country and the individual. In the past, there were many studies on whether receiving college education can improve personal income level and social productivity, but few people analyzed the return rate of basic education, that is, K-12 education. Compared with the difference of future income between higher education and vocational education, traditional research generally focuses on higher education, including our CBAS analysis. Since most people will carry out K-12 education, it is difficult to find differentiated data to prove the role of basic education. However, it is obvious that basic education is the basis of higher education, and the people with higher education must also have received basic education, so basic education obviously plays a role. This paper attempts to study the American K12 system through a conservative method and complete the CBAS analysis of the American k12 education system.

\section{The Plan Purpose and Description}

This paper analyzes the U.S. government's investment in K12.Through cost-benefit analysis, we will calculate the net social utility of the U.S. government's investment in basic education.

The $\mathrm{k} 12$ education system in the United States is divided into two parts. One part is the so-called public schools, which are operated and managed by the U.S. government and rely on government grants at all levels. Public school enrollment in the United States usually follows the principle of "Nearby Enrollment". In most cases, you can go to the public school in the school district where you live. The funds for public schools mainly come from the funds allocated by the state government from taxes, and the federal government provides scientific research, purchase of books and equipment and various subsidies to students; The child's tuition is free. Parents only need to pay part of the tuition and miscellaneous expenses and the expenses of occasional school activities. It can be said that they basically don't need to spend any money. The funding sources of private schools mainly come from tuition fees paid by students and funds from non-public sources, such as donations from companies, religious organizations, alumni and students' parents. Therefore, compared with free public schools, private schools have higher tuition fees.

In terms of education, the main personal benefit of education is the rise of individual future wages. In terms of society as a whole, the main benefit of education is that the future labor force has higher production capacity. At the same time, because many jobs need a certain education threshold, 
education will increase the number of domestic labor force that can meet the minimum work requirements and reduce the unemployment rate, Thus reducing the cost of unemployment benefits.

At the same time, education also needs costs. As we have mentioned before, public primary and secondary schools do not need tuition fees, so the cost of public education is the financial allocation of the government. For students entering private primary and secondary schools, their direct cost of education is their own tuition. Compared with receiving higher education, it may lead to the loss of current job opportunities. Due to the compulsory education act in the United States, k12 education can go to primary school at the age of 6 and drop out at the minimum age of 16 . In conclusion, the cost of K12 is the government appropriation for public education and the tuition fees charged by private schools.

\section{The Monetization of Benefits}

Here, let's calculate the benefits of $k 12$ education. We assume that the marginal output of labor is the income that workers can obtain. Therefore, we can think that for a person who has received education, the most direct benefits of education is that he has a higher income than those who have not received education. For the society, the social benefits also include that because many jobs require a certain education threshold, education will increase the number of domestic labor force that can meet the minimum work requirements. On the one hand, it will reduce the unemployment rate and reduce the distribution cost of unemployment benefits, On the other hand, this part of the population joined the production work because they received higher education, and the output of this part of the population is also the social benefits.

First, let's look at the impact of different levels of education on wages. In the report of the Georgetown University Center on education and the workforce, the college payoff: more education doesn't always mean more incomes, we can get data on income, age and education level. Since we only care about the role of basic education, we only need to pay attention to the results of lower than high school education and high school diploma. From the graphic display, it is obvious that the income level of senior high school and below is significantly different from that of senior high school graduation.

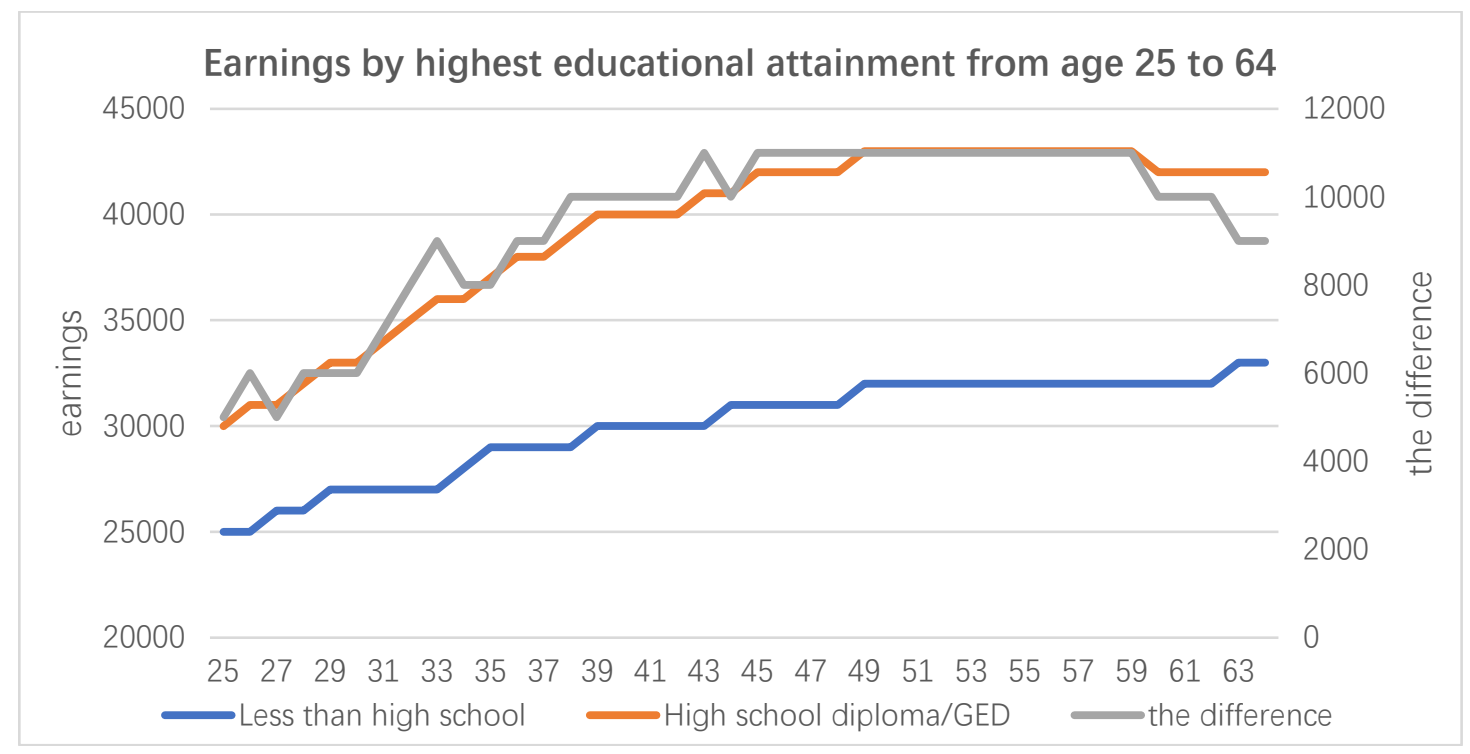

Figure 1. Earnings by highest educational attainment from age 25 to 64

According to the data from NECS, the employment rate was highest for 25- to 34-year-olds with a bachelor's or higher degree ( 86 percent). The employment rate for those with some college (78 percent) was higher than the rate for those who had only completed high school (69 percent), which was higher than the employment rate for those who had not completed high school (57 percent). 
We still only care about whether we graduate from high school, so it is obvious that the employment rate of high school graduates is $12 \%$ higher than that of non high school graduates. According to the data of the U.S. Department of labor by the end of 2019, although there are differences among States, on average, the average person can get $\$ 378$ in unemployment benefits per week. The following is the impact of different academic qualifications on the employment rate from the perspective of employment rate. The employment rate of people who have not graduated from high school can only be obtained and those with high school diploma is $13 \%$ lower on average, that is, through receiving complete $\mathrm{k} 12$ education, individuals will have a higher probability of getting a job.

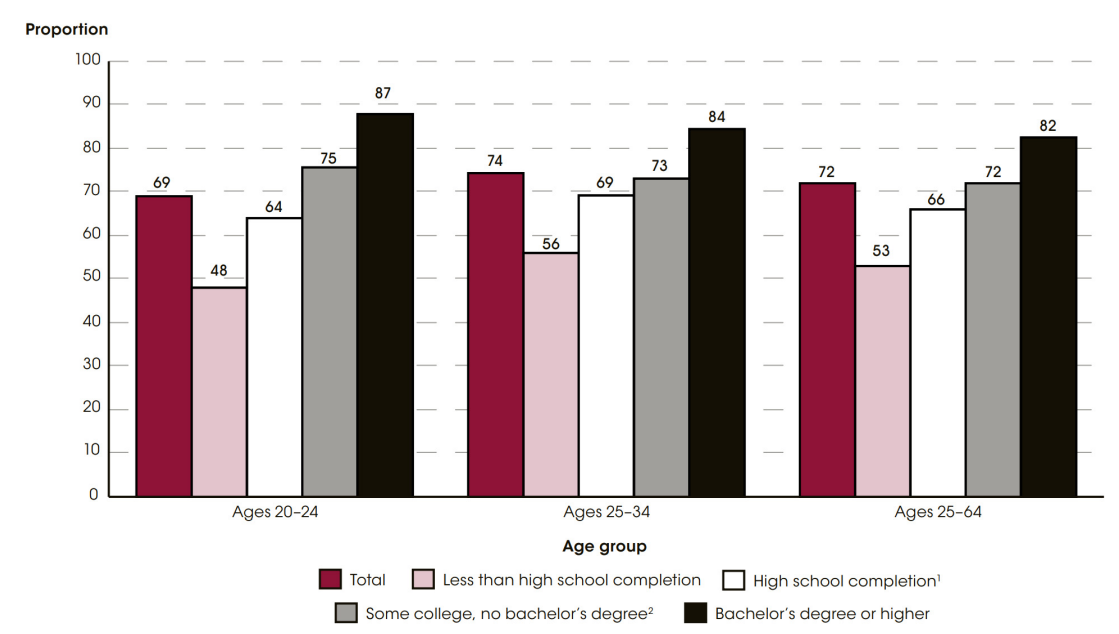

Figure 2. Employment rate at different educational levels

Finally, we also need to know how many can graduate from high school. According to the data from NECS, the high school graduation rate was $89 \%$ in 2010 . And $95 \%$ in 2020 .

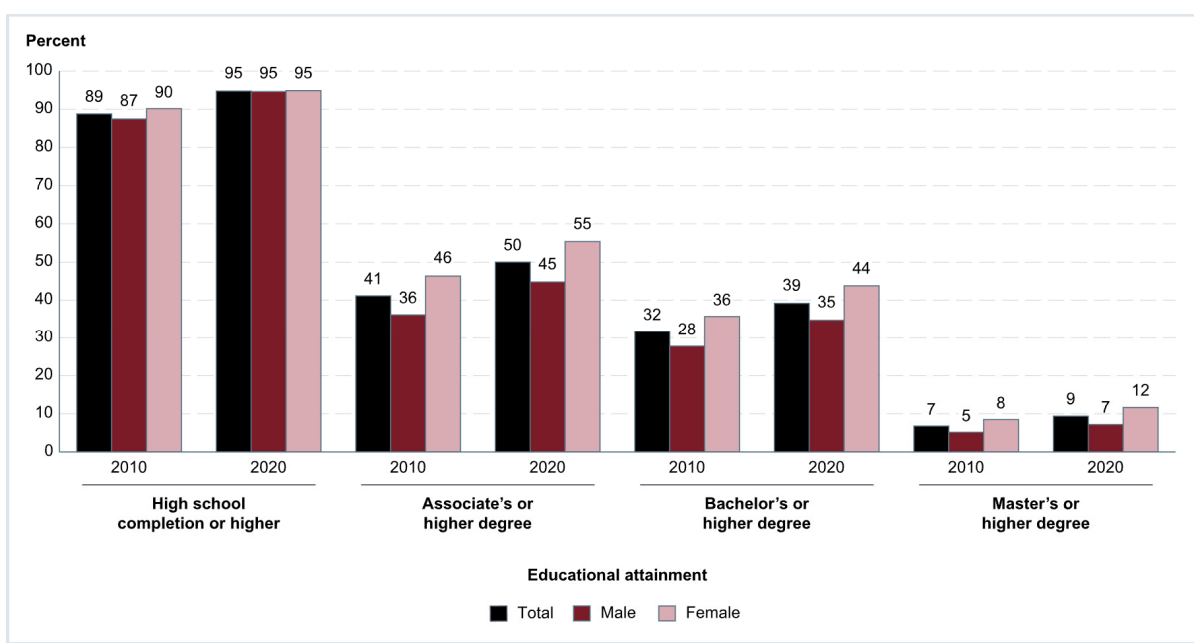

Figure 3. Education attainment at different educational levels

According to the above data, it is obvious that $\mathrm{K} 12$ project is a long-term and continuous project. We do not consider the income difference between the ages of 18-25 due to education. When calculating the income, we only consider the difference between the ages of 25-65. At the same time, we believe that only after receiving the high school diploma can we reap the complete benefits of k12 education. Because there is no high school diploma, we believe that there is no difference between the people who have not received education.

Based on the above data, we make certain assumptions to calculate the benefits brought by $\mathrm{k} 12$ education. 
1: According to NECS data, $95 \%$ of people have obtained high school diploma or above in 2020 , and there is a dropout rate of about 5.4 in 2017. Conservatively, we believe that the United States will enter a balanced period, and $94 \%$ of people of any age will obtain high school diploma or above, and about $6 \%$ of people have not graduated from high school.

2: Since whether there is a high school diploma will affect the employment rate and salary, we believe that there is no difference in the job market between those who have not completed high school education and those who have not received any education at all. According to historical data, we believe that the employment rate of people without a high school diploma after the age of 25 will be $13 \%$ lower than that of people with a high school diploma. At the same time, in real dollars, the difference between salaries is the difference data given in the report of the Georgetown University Center on education and the workforce. Before the age of 25 , there is no difference between receiving a diploma or not.

3: We believe that out of humanitarian concern, the US government's unemployment subsidy to the unemployed will not change with inflation, that is, it is US \$378 per week. According to the data of the U.S. Department of labor, before the epidemic, the average time for ordinary workers to receive unemployment benefits was about 15 weeks. We calculate according to this data.

4: We assume that the population structure of the United States will not change significantly in the future, so we assume that the annual enrollment is about 56 million.

5: According to US Department of transportation's benefit cost analysis guidance for discrete grant programs., we assume that the analysis discount rate of the modified project is $7 \%$.

With the above assumptions, we can calculate the income generated by k12 education. It is assumed that the average graduation age of high school is 18 years old and 0 fiffer in the first seven years.

We first calculate the income due to wage differences. Calculate the net present value of each person's income difference due to different educational background. The following table shows the calculation process.

Table 1. Net present value of income difference caused by different educational background

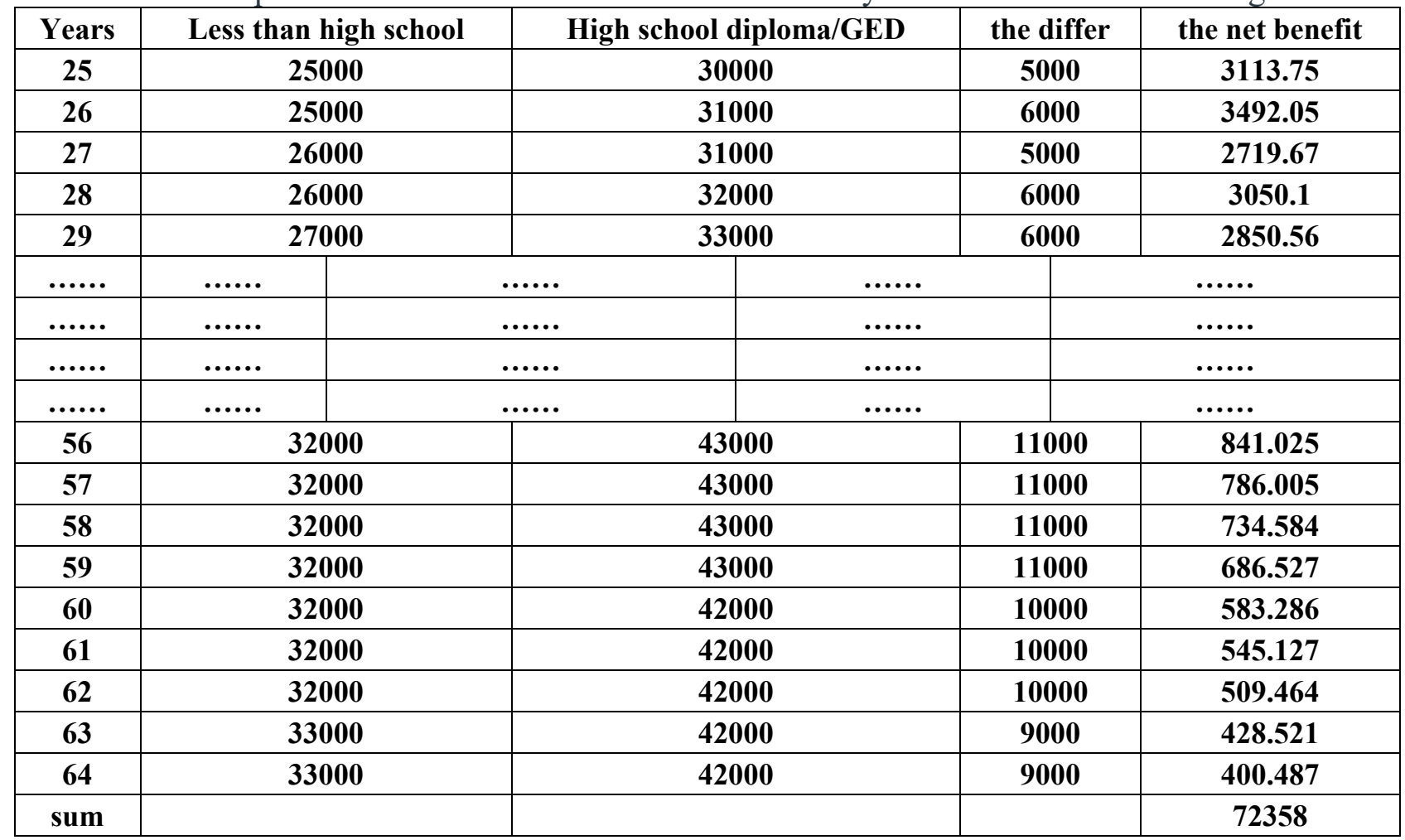


On average, the employment rate of those who graduated from high school is $53 \%$, so the income of this part is: 56 million $* 0.53 * 72358=21475$ million $\$$.

The increase in employment due to the existence of high school diploma. Since the number of people without high school graduation is about $6 \%$, the employment rate of this group is $13 \%$ lower than that of people with high school graduation, high school graduation will make 56 million * 0.94 $* 0.13=6843200$ people employed. The income of this group consists of two parts: one is the wage income obtained due to additional employment, which is the annual net wage, and the present value of each person's income is $323881 \$$.

The overall social calculation is: $6843200 * 323881=221640000000 \$$.

Table 2. Net present value of employment due to high school graduation

\begin{tabular}{|c|c|c|c|}
\hline years & Less than high school & High school diploma/GED & the net benefit \\
\hline 25 & 25000 & 30000 & 18682.5 \\
\hline 26 & 25000 & 31000 & 18042.3 \\
\hline 27 & 26000 & 31000 & 16861.9 \\
\hline 28 & 26000 & 32000 & 16267.2 \\
\hline 29 & 27000 & 33000 & 15678.1 \\
\hline ...... & ...... & ...... & ...... \\
\hline$\ldots \ldots$ & $\ldots \ldots$ & $\ldots \ldots$ & ...... \\
\hline$\ldots \ldots$. & ...... & ...... & ...... \\
\hline$\ldots \ldots$ & $\ldots \ldots$ & $\ldots \ldots$ & $\ldots \ldots$ \\
\hline 56 & 32000 & 43000 & 3287.64 \\
\hline 57 & 32000 & 43000 & 3072.57 \\
\hline 58 & 32000 & 43000 & 2871.56 \\
\hline 59 & 32000 & 43000 & 2683.7 \\
\hline 60 & 32000 & 42000 & 2449.8 \\
\hline 61 & 32000 & 42000 & 2289.53 \\
\hline 62 & 32000 & 42000 & 2139.75 \\
\hline 63 & 33000 & 42000 & 1999.77 \\
\hline 64 & 33000 & 42000 & 1868.94 \\
\hline sum & & & 323881 \\
\hline
\end{tabular}

The third part is the saved unemployment subsidy. Based on 378 \$per person per week and 15 weeks per year, it is calculated as 5678 \$per year. From the age of 25 to 64, it can be calculated that the net value obtained by individuals through unemployment subsidies is 50440, and the present value of saved unemployment subsidies is $6843200 * 50440=345170000000 \$$.

To sum up, the present value of income is 47091 billion.

\section{The Monetization of Costs}

Here, we need to calculate the cost of k12 education. According to the data from the NCES, from 2017 to 2018, revenues for public elementary and secondary schools of the United States is 734244219000 \$, which is 14518 dollars per student on average. This figure was \$13954 in 20162017. The following figure shows the fiscal revenue of public primary and secondary schools since 1994. 


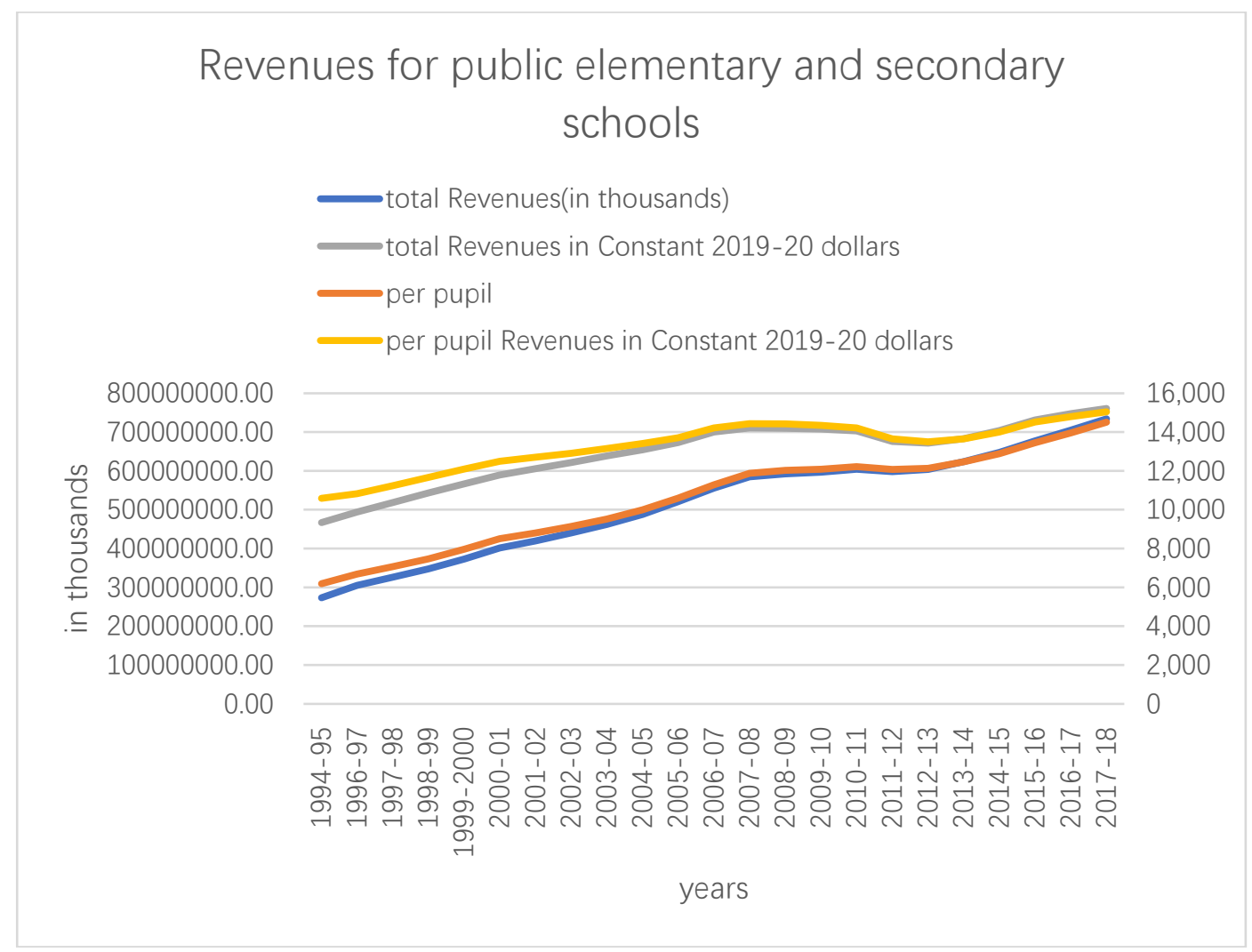

Figure 4. Revenues for public elementary and secondary schools

Of course, we have not calculated the cost of education in private schools. A survey of 1100 private schools in the United States found that the average tuition fee of full-time private schools in the United States is $\$ 19100$ a year. Boarding schools have higher tuition fees, averaging $\$ 45400$ a year, and some even exceed $\$ 60000$. This data source is an online article, and the data source is not marked, but I think it has certain reference significance and there is no more data support. We will calculate it at 19100 yuan per student for the time being.

According to NECS data, about $10 \%$ of students choose private schools, so we can roughly calculate the total number of students receiving $\mathrm{k} 12$ education and the total cost of society in $\mathrm{k} 12$ education system every year according to the number of students in public schools.

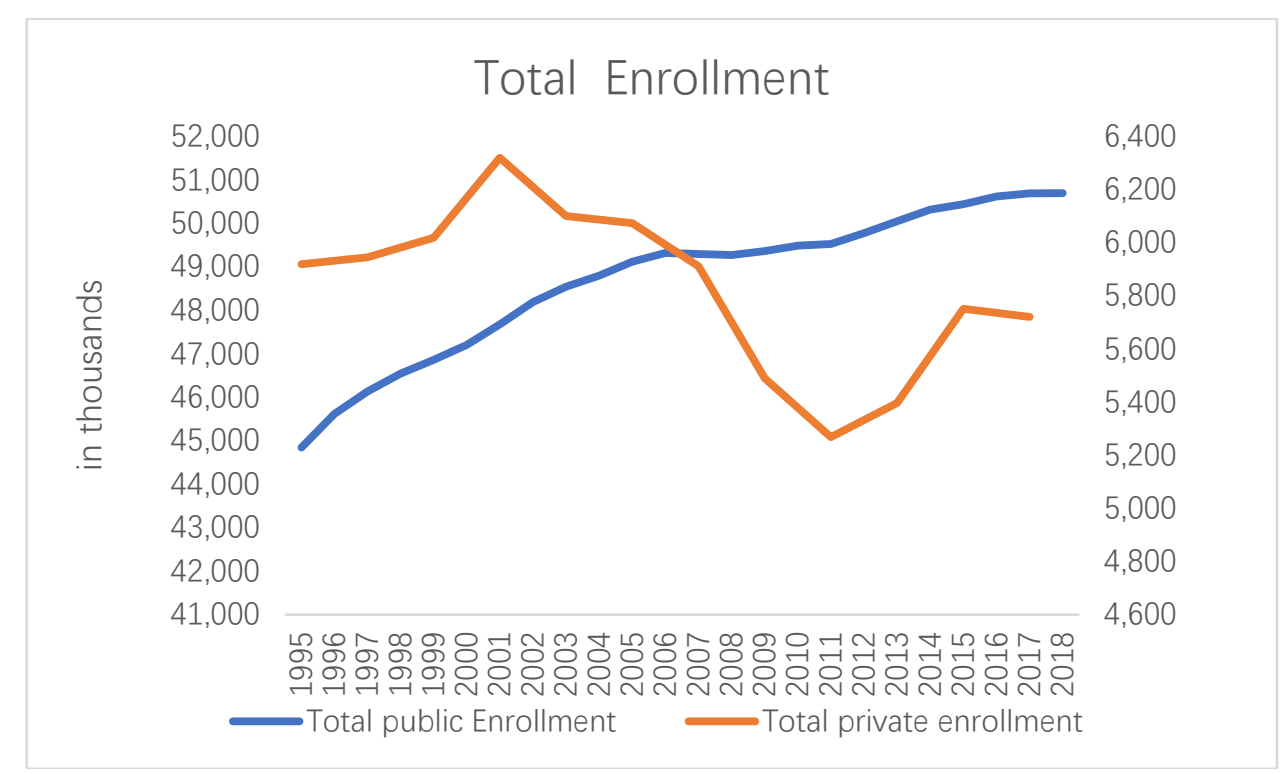

Figure 5. Total Enrollment 
In the process of calculating income, we have assumed that the population structure of the United States is stable, so we can assume that the number of people admitted to public and private schools is also stable in the subsequent calculation.

In 2017, the total income of private schools was the total enrollment * average tuition fees, which was $5720000 * 19100=109252000000 \$$.

Based on the above data, from 2017 to 2018 , the total cost of the entire k12 education system in the United States was $345170000000+109252000000=843496219000 \$$.

\section{The Findings of CBAs}

Obviously, in the above, we calculated the cost and income analysis of k12 education respectively. The present value of the income of k12 education is as high as 47091 billion $\$$, while the cost of $k 12$ education is 8435 billion $\$$. From the results, the income of basic education is $556 \%$ of the cost, which is obviously very gratifying. Compared with the yield of general investment, education is obviously one of the most effective investment projects in the country.

Of course, the data show that higher education will bring higher rate of return. Even if you fail to get a university degree, the employment rate and average wage will further improve. Further analysis can analyze the cost-benefit analysis of education at other levels. Of course, this paper also has its own limitations. After all, the article gives a lot of assumptions for the convenience of calculation. For example, we assume that the future wage structure and tuition fees are consistent with the current ones. However, these assumptions do not affect our analysis. After all, we have reason to believe that the growth rate of future wages will be higher than the current tuition fee growth rate. For more detailed research, our future research can further release these assumptions to complete cost-benefit analysis.

\section{The Conclusion of Our Analysis}

Through analysis, this paper finds the following conclusions:

1: Every year, the income generated by basic education is as high as 47091 billion, almost $20 \%$ of the US GDP, and this part comes from three parts. The main source is the job opportunities obtained due to reaching a higher work threshold. This part of the income reaches 22164 billion, followed by higher productivity level, and this part of the income is 21475 billion, Finally, it reduced the distribution of unemployment benefits, which reduced the social cost, and the income of this part was 3451.7 billion.

2: Since there is no job crowding, the total cost of basic education is tuition, while the tuition expenditure of public education is borne by federal governments at all levels, and the cost of private education is tuition. Therefore, according to the calculation, we can calculate that the total cost of basic education is 8435 billion, of which the cost of public education is $7342 \mathrm{billion}$, the cost of private education is about 1093billion.

3: According to the comprehensive cost-benefit analysis, the net income of basic education reached 38656 billion, accounting for $18.5 \%$ of the national GDP, and the return on investment reached an amazing $458 \%$. Obviously, education is really a very good investment.

4: Further analysis can be extended to the cost-benefit analysis of higher education level. Of course, if the data allows, more accurate results can be obtained through appropriate assumptions.

\section{References}

[1] Anthony P. Carnevale, Ban Cheah, Emma Wenzinger; The College Payoff: More Education Doesn't Always Mean More Earnings [R]. the Georgetown University Center on education and the workforce, 2021.

[2] Joel McFarl, Bill Hussar; The Condition of Education 2019 [R]. National Center for Education Statistics, 2021. An Application of Cost-Benefit Analysis to Management Education. 
Volume 17 (2022)

[3] Boardman Greenberg Vining Weimer; Cost-Benefit Analysis Concepts and Practice [M]. Pearson, 2014.

[4] Samuel Paul; An Application of Cost-Benefit Analysis to Management Education[J]. Journal of political economy, 1972. 